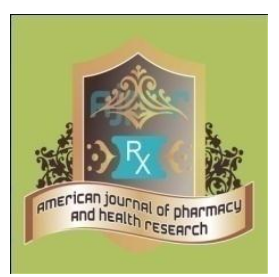

Research Article AMERICAN JOURNAL OF PHARMACY AND HEALTH RESEARCH

www.ajphr.com

2018, Volume 6, Issue 05

ISSN: 2321-3647(online)

\title{
Correlation Analysis of ground water: A Case Study in Selected Areas Near Tirupati, India
}

\author{
S.V. Dorairaju ${ }^{1,3}$, C. Narasimha Rao $^{2}$, P.V. Chalapathi ${ }^{*}$ \\ 1.Department of Chemistry, Rayalaseema University, Kurnool, 518002, Andhra Pradesh, \\ India. \\ 2.Department of Chemistry, S. V. University, Tirupati, 517502, Andhra Pradesh, India. \\ 3.Department of Chemistry, S.V. Arts Degree and P.G. College, Tirupati, 517502 Andhra \\ Pradesh, India.
}

\begin{abstract}
Ground water quality and its impact on human health in an industrial area near Tirupati, India has been assessed. Water samples were collected from 40 different locations of Vadamala Pet near Tirupati and analyzed for physicochemical parameters such as $\mathrm{pH}$, electrical conductivity, total dissolved solids, total hardness, calcium, chlorides, sulphates, nitrates and dissolved oxygen etc. The found values of physicochemical parameters were compared with the World Health Organization (WHO) water quality standards. Based on the physico-chemical analysis and correlation studies, it was found that ground water of some of the studied areas was polluted and not suitable for drinking purpose. Thus the ground water of such areas needs purification before drinking.
\end{abstract}

Keywords: Ground water, physicochemical parameters, purification, total dissolved solids, hardness. 


\section{INTRODUCTION}

Fresh water is finite resource, essential for agriculture, industry and even human existence, without fresh water of adequate quantity and quality, sustainable development will not be possible $\mathrm{e}^{1-3}$. There is an extensive literature, which stresses deterioration of water quality ${ }^{4-8}$. The addition of various kinds of pollutants and nutrients through the agency sewage, industrial effluents, agricultural runoff etc. in to the water bodies brings about a series of changes in the physicochemical and characteristics of water, which have been the subject of several investigations. Fresh water resource is becoming day-by-day at the faster rate of deterioration ${ }^{9-11}$.

Today there is trace contamination not only of surface water but also of groundwater bodies, which are susceptible to leaching from waste dumps, mine tailings and industrial production sites. Soils receiving repeated applications of organic manures, fungicides and pesticides have exhibited high concentration of extractable heavy metals and that thereby increase their concentration in runoff, while falling as rain, water picks up small amounts of gases, ions, dust and particulate matter from the atmosphere. These added substances may be arbitrarily classified as biological, chemical (both organic and inorganic), physical and radiological impurities. They include industrial and commercial solvents, metal and acid salts, sediments, pesticides, herbicides, plant nutrients, radioactive materials, decaying animal and vegetable matter and living microorganisms, such as algae, bacteria and viruses.

These impurities may give water a bad taste, color, odor or turbidity and cause hardness, corrosiveness, staining or frothing. Several researchers carried out physicochemical analysis of groundwater to assess its pollution.

Tirupati, a major economical and educational hub in the southern region of the state. People of rural areas located around Tirupati are mainly dependent on ground water for drinking and other domestic needs. Unscientific disposal of waste water from industries is contaminating the ground water of Tirupati and surroundings. In addition, high floating population leads to disposal of much domestic waste which finally contaminates ground water. As no detailed study on ground water quality has been yet reported in this area, we undertook a detail survey to understand the contamination and consequent health effects.

\section{MATERIALS AND METHOD}

The ground water samples were collected in clean and dry polythene bottles, filtered using Whatmann no.42 filter paper and stored. The samples were collected during summer season because the mineral content in water is likely to reach the maximum. The temperature of the 
samples was measured in the field itself at the time of collection. The collected samples were kept in the refrigerator, maintained at $4^{\circ} \mathrm{C}$ and analyzed for a few important parameters in order to have an idea on the quality of drinking water. The average results were tabulated.

Electrical conductivity values were measured using Elico CM 180 Conductivity Bridge. Total alkalinity was evaluated by titration with standard $0.1 \mathrm{M} \mathrm{HCl}$ using methyl orange and phenolphthalein as indicators. Standard procedures involving spectrophotometry, flame photometry and volumetry were used for the determination of hardness, total dissolved solids (TDS), sulphate, chloride, nitrate, calcium, magnesium and iron. All the chemicals used were of AR grade.

\section{RESULTS AND DISCUSSION}

Water samples were collected from 40 different locations of Vadamala Pet near Tirupati and analyzed for physicochemical parameters such as $\mathrm{pH}$, electrical conductivity, total dissolved solids, total hardness, calcium, chlorides, sulphates, nitrates and dissolved oxygen etc. The found values of physicochemical parameters were compared with the World Health Organization (WHO) water quality standards.

\section{Chemical parameters}

The limit of $\mathrm{pH}$ value for drinking water is specified as 6.5 to 8.5 . $\mathrm{pH}$ value in the studied area varied between 6.2-8.2. All the sampling points showed $\mathrm{pH}$ values within the prescribed limit by WHO. Abnormal values of $\mathrm{pH}$ causes bitter taste to water, affects mucous membrane, causes corrosion and also affests aquatic life.

The total hardness is relatively high in all samples due to the presence of calcium, magnesium, chloride and sulphate ions. High amount of hardness in drinking water leads to heart diseases and kidney stone formation. 37 sampling points showed hardness values within the prescribed limit and 3 sampling points showed higher hardness values than the prescribed limit by WHO. Exceeding the permissible limit of hardness causes poor lathering with soap, deterioration of the quality of clothes, scale formation and skin irritation.

Various ionic species that contribute to the alkalinity include hydroxide, carbonates, bicarbonates and organic acids. 2 sampling points showed higher alkalinity values than the prescribed limit by WHO. Water with high amount of alkalinity results in unpleasant taste to water and it turns boiled rice to yellowish colour.

If calcium is present beyond the maximum acceptable limit, it causes incrustation of pipes, poor lathering and deterioration of the quality of clothes. 4 sampling points showed higher calcium 
values than the limit prescribed by WHO. Too high magnesium will adversely affect crop yields as the soils become more alkaline. 3 sampling points showed higher magnesium values than the limit prescribed by WHO. The excess amount of iron causes slight toxicity; gives stringent taste to water and can cause staining laundry and porcelain. 5 sampling points showed higher iron values than the prescribed limit by WHO.

High nitrate concentration causes methemoglobinemia and cyanosis. All the sampling points showed nitrate values within the prescribed limit by WHO. In the present study the sampling points in which nitrate has been found to be high can result in formation of nitroso-amines which are carcinogenic. The permissible limit of chloride in drinking water is $250 \mathrm{ppm}$. According to ICMR the maximum permissible limit for chloride in drinking water is $250 \mathrm{mg} / \mathrm{L} .8$ sampling points showed higher chloride values than the prescribed limit by WHO. The higher values of chloride can cause corrosion and pitting of iron pipes and plates. High amount of sulphate imparts bitter taste to water. Also, this will cause laxative effect to the children in hot weather climates. 6 sampling points showed higher sulphate values than the prescribed limit by WHO. Ingestion of water with high concentration of sulphates causes laxative effect and gastro-intestinal irritation.

\section{Biological parameters}

High amount of DO imparts good taste to water. 4 sampling points showed higher DO values than the prescribed limit by WHO. Water with high COD indicates that there is inadequate oxygen available in the water samples. All the sampling points showed BOD values within the limit prescribed by WHO. Ground water with high value of BOD is due to microbial activities related to the dumpsites.

\section{Physical parameters}

When electrical conductivity value exists at $3000 \mu \mathrm{mho} / \mathrm{cm}$, the generation of almost all the crops would be affected and it may result in much reduced yield. Electrical conductivity of water is considered to be an indication of the total dissolved salt content. 5 sampling points showed higher conductivity than the prescribed limit by WHO. If drinking water has high conductivity, it indicates the presence of high amount of dissolved inorganic substances in ionized form.

High Total Dissolved Solids (TDS) of studied area may be due to the ground water pollution by the residential waste. The residential waste is discharged into the pits, ponds due to which the waste migrates down to the water table and moreover there is a possibility of dissolution of rocky materials in the area. TDS in groundwater can also be due to natural sources such as sewage, urban runoff and industrial wastes. 8 sampling points showed higher TDS than the prescribed limit by 
WHO. Continuous consumption of water with high TDS content can cause gastro intestinal irritation. It also causes undesirable taste and corrosion or incrustation.

\section{Correlation Studies}

The regression equations for the parameters having significant correlation coefficients are useful to estimate the concentration of other constituents. The study of correlation coefficients of water quality parameters helps to assess the overall water quality. Correlation co efficient amongst various parameters of water samples are presented in table 1. Alkalinity shows significant correlation with calcium indicating that the alkaline nature of ground water is mainly due to calcium salts. Calcium shows good correlation with chlorides indicating that calcium is associated with chlorides in ground water of the studied area. Conductivity shows significant correlation with calcium, chlorides and DO which reveals that conductance of water samples is mainly due to calcium and chlorides in the ground water of the studied area.

Table 1 Correlation Coefficient values of various physico-chemical parameters

\begin{tabular}{|c|c|c|c|c|c|c|c|c|c|c|c|c|c|c|c|c|c|}
\hline & pH & TH & TA & $\mathrm{Ca}^{2+}$ & $\mathbf{M g}^{2+}$ & $\mathrm{Fe}^{2+}$ & $\mathrm{NO}_{3}{ }^{-}$ & $\mathrm{Cl}^{-}$ & $\mathrm{SO}_{4}{ }^{2-}$ & DO & COD & BOD & Temp & Cond & TS & TDS & \begin{tabular}{|l|}
$\mathbf{T}$ \\
$\mathbf{S C}$
\end{tabular} \\
\hline $\mathrm{pH}$ & 1 & & & & & & & & & & & & & & & & \\
\hline $\mathrm{TH}$ & 0.50424 & & & & & & & & & & & & & & & & \\
\hline TA & 0.73195 & 50.67313 & 1 & & & & & & & & & & & & & & \\
\hline $\mathrm{Ca}^{2+}$ & 0.91967 & 70.50541 & 0.69553 & 1 & & & & & & & & & & & & & \\
\hline $\mathrm{Mg}^{2+}$ & 0.71021 & 0.30663 & 0.61598 & 0.66345 & 1 & & & & & & & & & & & & \\
\hline $\mathrm{Fe}^{2+}$ & -0.4587 & -0.1986 & -0.4187 & -0.4475 & -0.3275 & 1 & & & & & & & & & & & \\
\hline $\mathrm{NO}_{3}^{-}$ & 0.24747 & 0.28392 & 0.11481 & 0.24877 & 0.11834 & -0.1927 & 1 & & & & & & & & & & \\
\hline $\mathrm{Cl}^{-}$ & 0.88408 & 0.47211 & 0.70298 & 0.94259 & \begin{tabular}{|l|}
0.70933 \\
\end{tabular} & $\mid-0.4248$ & \begin{tabular}{|l|}
0.22922 \\
\end{tabular} & 1 & & & & & & & & & \\
\hline $\mathrm{SO}_{4}{ }^{2-}$ & -0.1043 & \begin{tabular}{|l|}
-0.1301 \\
\end{tabular} & -0.1455 & -0.0189 & \begin{tabular}{|l|}
-0.1151 \\
\end{tabular} & -0.0083 & 0.1074 & \begin{tabular}{|l|}
-0.0454 \\
\end{tabular} & 1 & & & & & & & & \\
\hline DO & -0.96 & -0.5512 & -0.7713 & -0.955 & $\mid-0.7344$ & 0.41018 & -0.2509 & -0.9445 & 0.1417 & 1 & & & & & & & \\
\hline COD & -0.565 & -0.2855 & -0.4375 & -0.5244 & $\mid-0.4662$ & -0.0003 & -0.1327 & -0.5644 & 0.22061 & 0.65381 & 1 & & & & & & \\
\hline BOD & 0.98215 & 0.53921 & 0.74389 & 0.9365 & 0.72478 & -0.4745 & 0.23196 & 0.92327 & -0.1665 & -0.9728 & \begin{tabular}{|c|}
-0.5878 \\
\end{tabular} & 1 & & & & & \\
\hline Temp & -0.2758 & -0.0949 & -0.1905 & -0.3073 & -0.1808 & 0.22381 & 0.08073 & -0.356 & 0.22821 & 0.30919 & 0.2613 & -0.3193 & 1 & & & & \\
\hline Cond & 0.9443 & 0.48245 & 0.6825 & 0.95358 & 0.69029 & -0.4827 & 0.23157 & 0.95355 & -0.0621 & -0.9576 & -0.5318 & 0.96102 & -0.3178 & 1 & & & \\
\hline TS & 0.29405 & -0.0056 & 0.00014 & 0.36166 & 0.24667 & -0.1986 & 0.01817 & 0.34418 & 0.12749 & -0.2741 & 0.02643 & 0.29283 & 0.04805 & 0.38133 & 1 & & \\
\hline TDS & 0.26182 & -0.001 & -0.0108 & 0.3364 & 0.22112 & -0.1687 & -0.0434 & 0.33422 & 0.12402 & -0.2488 & 0.04284 & \begin{tabular}{|l|l|}
0.268 \\
\end{tabular} & 0.03328 & 0.36181 & 0.99212 & 1 & \\
\hline TSS & 0.22639 & -0.0363 & 0.08712 & 0.16381 & 0.178 & -0.2178 & 0.48883 & 0.04355 & 0.01436 & -0.1732 & -0.1336 & 0.16749 & 0.11277 & 0.1159 & -0.0415 & 0.1664 & \begin{tabular}{|l}
0. \\
11 \\
27 \\
7
\end{tabular} \\
\hline
\end{tabular}

*TH= Total Hardness, TA= Total Alkalinity, DO=Dissolved Oxyen, COD=Chemical Oxyen

Demand, BOD=Biochemical Oxyen Demand, Temp=Temperature, Cond=Conductivity,

TS=Total Solids, TDS=Total Dissolved Solids, TSS=Total Suspended Solids

All the parameters measured as $\mathrm{mg} / \mathrm{L}$ except Temperature $\left({ }^{\circ} \mathrm{C}\right)$ and Conductivity $(\mu \mathrm{S} / \mathrm{cm}$

CONCLUSION

Industrialization and urbanization affected the ground water quality due to over exploitation of 
resources and improper waste disposal practices. According to WHO, nearly $80 \%$ of all the diseases in human beings are caused by water. Based on the results obtained for physicochemical analysis of ground water samples collected from different locations in the studied Vadamala Pet area, near Tirupati, it can be concluded that in some samples water quality parameters were beyond the permissible limit prescribed by WHO. The diseases may occur due to the lack of water quality in the studied area. Hence, drinking water pollution should be controlled by the proper environment management plan. Ground water of this area should be pretreated to make suitable for drinking and to maintain proper health conditions of people living in this area.

\section{REFERENCES}

1. Madhusudan Yaduvams E, Ranga Rao SV, Venkata Ramana CH, Byragi Reddy T. Physico-Chemical Analysis of Ground Water in the Selected Area of Visakhapatnam, AP, India. Int.J.Curr.Microbiol.App.Sci. 2017; 6(12): 1252-1258.

2. Bhattacharyya BG. Physicochemical analysis of pond water in Purba Barddhaman, West Bengal, India. Int. Res. J. Environmental Sci. 2018; 7(2): 54-59.

3. Dorai Raju SV, Narasimha Rao C, Bujagendra Raju M, Chalapathi PV. Analysis of drinking water quality and its impact on human health in Chandragiri, near Tirupati, India. Biosci., Biotech. Res. Asia. . 2013; 10(1): 379-381.

4. Dorai Raju SV, Narasimha Rao C, Bujagendra Raju M, Chalapathi PV. Chemical properties of Drinking water of Renigunta, near Tirupati, Andhra Pradesh, India and its Impact on human health. Curr. World Environ. 2012; 7(1): 37-39.

5. Kanungo S, Kumar Bhuyan N, Hemanta Kumar P. Assessment of the Water Quality Standard of Brahmani River in terms of Physico-Chemical Parameters. Int. J. Sci. Res. Manag. 2018, 6(4): 50-57.

6. Nidhi Jain N. Physico-chemical assessment of water quality in one part of Hinjewadi, Pune Maharashtra (India). Int. J. Sci. Res. Eng. Tech. 2018; 7(1): 1-9.

7. Ignatius Navis K, Tharaa K, Dheenadayalanb MS. Physico-Chemical Study of the Ground Water Quality at Selected Locations in Periyakulam, Theni district, Tamilnadu, India. Mater Today. 5 (2018) 422-428

8. Faiza T,Risjani Y, Sasmito Djati M, Yanuwiadi B, Setyo Leksono A. The Analysis of the Physical and Chemical Properties of the Water Quality in the Rainy Season in the Sumber Maron River - Kepanjen, Malang - Indonesia. Resources and Environment 2018, 8(1): 15 . 
9. Kiran Kumar V, Jianjun W, Long C, Tianma Y, McCarthy AJ, Sekar R. Assessment of Water Quality and Identification of Pollution Risk Locations in Tiaoxi River, China. Water 2018, 10(183): 1-18.

10. Snehalata K, Sandhya Kiran JK. Physico-Chemical Analysis of Ground Water. Int. J. Innov. Res. Sci. Eng. Technol. 2018; 7(1): 269-276.

11. Shahidul Islam M, Mohanta SC, Bakar Siddique MA, Al-Mamun MA, Hossain N, Hafsa Bithi U. Physico-chemical assessment of water quality parameters in Rupsha river of Khulna region, Bangladesh. Int. J. Eng. Sci. 2018; 7(1): 57-62.

AJPHR is

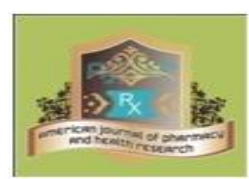

Peer-reviewed monthly

Rapid publication

Submit your next manuscript at editor@ajphr.com / editor.ajphr@gmail.com 